DIGITALCOMMONS

—@WAYNESTATE-
Michigan Journal of Counseling:

Research, Theory and Practice

$8-1-2002$

\title{
Counseling and Naturopathy: Exploring Collaboration between Counseling and an Alternative Medical Model
}

Cheryl M. Milde

Southeast Missouri State University, cmilde@semo.edu

Diane Dempsey Marr

Whitworth College

Follow this and additional works at: https://digitalcommons.wayne.edu/mijoc

\section{Recommended Citation}

Milde, C. M, \& Marr, D. D. (2002). Counseling and Naturopathy: Exploring Collaboration between Counseling and an Alternative Medical Model, Dimensions of Counseling, 30(2), 8-13. doi:10.22237/mijoc/1028160120

This Article is brought to you for free and open access by the Open Access Journals at DigitalCommons@WayneState. It has been accepted for inclusion in Michigan Journal of Counseling: Research, Theory and Practice by an authorized editor of DigitalCommons@WayneState. 


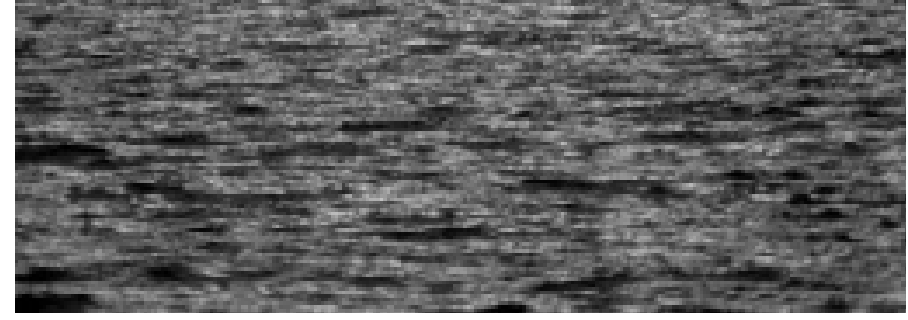

\section{Counseling and Nafuropathy: Exploring Collaboration between Counseling and an Alternative Medical Model}

\author{
Cheryl M. Milde, Ph.D. \\ Southeast Missouri State University \\ Diane Dempsey Marr, Ph.D. \\ Whitworth College
}

Cheryl M. Milde, Ph.D. is an assistant professor in the Department of Educational Administration and Counseling at Southeast Missouri State University. Diane Dempsey Marr, Ph.D. is an associate professor of counseling at Whitworth College and chair of the Washington Counseling Association's Bylaws and Ethics Committee. The authors thank Dr. Todd Schlapfer, N.D. of Coeur d'Alene Healing Arts for his generous support of this project. Correspondence regarding this article can be sent to: Cheryl M. Milde, Ph.D., Educational Administration and Counseling, Mail Stop 5550, Southeast Missouri State University, Cape Girardeau, MO 63701. Electronic mail may be sent to cmilde@semo.edu.
Given a higher incidence of many common chronic conditions, the management of "difficult to heal" clients has given counseling a greater role within medical circles. Since many of these chronic conditions may be a result of environmental exposure to pathogens, the role of alternative or natural healing approaches has become increasingly popular. This paper provides a brief overview of the naturopathic medical model, and examines counselors' collaboration with an alternative medical model with regard to professional counselor practice, training, and ethics.

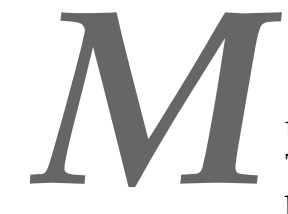

uch has been written about the mind-body connection. The pendulum has swung from the view that illness is brought about by "evil spirits" or is an unfortunate happenstance to the perspective that illness is caused by individuals' general lack of fitness-either physical or spiritual. Guilt from having an illness may stem from the popular view that if one does all the right things, then illness can be avoided. This view of wellness, although intended to empower, can leave the physically ill wondering if they are in some way to blame. Patients may question if there is a chicken or egg dilemma-which came first? Has the physical illness led to mental stress, depression and lack of motivation or have these factors contributed to the physical illness that seems unrelenting? It is likely that this debate will continue well into the new millennium.

Conventional medicine's impressive success with aggressive diseases such as small pox, polio, diphtheria, and cholera has increased the survival rate of our youngest citizens while, in turn, lengthening the average 
life expectancy of adults. This shift in focus and frequency from infectious maladies to chronic or degenerative conditions has fueled the popularity of holism and alternative medicine (Flint, 1998; Lyddon, 1987). Illnesses such as chronic fatigue syndrome (Albrecht \& Wallace, 1998), fibromyalgia, and various forms of arthritis, to name a few, are often difficult to diagnose and to treat. Consequently, many people have found the healing they desire to be elusive. Some of the most heart-wrenching and frustrating patients in medical doctors' offices are those who suffer from these "difficult to diagnose and to treat" chronic illnesses. Whether unable or unwilling to take steps to better their health, such patients may continue to request assistance even after finding little or no relief from known treatment protocols. Not only are these patients time-consuming for medical doctors, they challenge the medical profession's foundational training to "fix" what is wrong.

The dissatisfaction with conventional medicine's sometimes fragmented, impersonal, and costly approach to treating health problems has resulted in more and more clients turning to alternative health care providers (Bar, 1998). The holistic perspective of alternative health care espouses a basic belief that also underlies counseling practice-empowering the individual-and offering hope to the suffering where once there was none. The mindbody connection is affirmed and holism encourages patients to develop their personal power in cultivating and maintaining healthy lifestyles within a supportive climate. Interestingly, a recent survey of the nation's 125 conventional medical schools revealed that of the 117 schools responding, 75 reported that they offered alternative medical electives or included such topics in required courses (Wetzel, Eisenberg, \& Kaptchuk, 1998).

An increased dialogue concerning holistic health issues has been noted in professional mental health publications (Collins, 1997; Farberman \& Haber, 1998; Haber, 1998; Johnson, 1997) examining the potential of alternative treatments to enhance the physical and mental health of clients, especially those who have not found adequate resolution of health problems through conventional medicine. Included in the discourse have been possible drawbacks of reaching beyond the conventional medical community, especially with regard to the lack of continuity observed in regulating alternative practitioners. he holistic perspective of alfernative health

care espouses a basic belief that also underlies counseling practiceempowering the individual一and offering hope to the suffering where once there was none.

\section{The Counseling Profession's Role in Adjunct Holistic Medical Care}

With the increase in chronic conditions and their associated stresses, counseling has become more and more acceptable as an adjunct to the general practice of conventional and alternative medicine. Many primary medical practices have added counselors to their staffs. Especially popular in Great Britain, counselors are viewed as liaisons between patients and doctors (Hemmings, 2000). Counselors can use their specialized training to assist patients in several areas such as communication, advocacy, stress management, pain control, and behavioral changes.

As the trend toward inclusion of professional counselors continues, counselors will likely find themselves among the therapeutic agents in comprehensive holistic health care programs (Papadopoulus \& Bor, 1995). The mental health profession has traditionally taken a cautious stance with regard to the participation in natural medicine health care; however, growing populations of people who prefer alternative medical care, or who use programs offering holistic healing concepts are talking to counselors about their health care choices. Often such alternative care is adjunct to patients' conventional medical care and is frequently sought without the knowledge of the primary care physicians. Given this reality, counselors are encouraged to take inventory of the knowledge they possess regarding alternative approaches and to explore their personal attitude toward holistic health care. How will these two factors impact the way in which counselors assist their clients? As we entertain the idea of broadening our views on health care beyond conventional approaches, the counseling profession must ask how this will influence service provision, but also how standards for practice, training, professional collaboration, and ethical behavior can be expanded to encompass a new perspective.

\section{Naturopathy: A Possible Choice}

For alternative approaches to be viewed as legitimate health care options, increased rigor in the preparation of providers, the standards of care, and the regulation of health care products must also be realized. One wellcoordinated option is naturopathic medicine.

Naturopathy is defined as a distinct system of primary healthcare-an art, science, philosophy and practice of diagnosis, treatment and prevention of illness. The techniques of naturopathic medicine include modern and traditional, scientific and empirical methods (American 
Association of Naturopathic

Physicians, 2002).

The naturopath's holistic view of health encompasses physical, mental, and spiritual well-being. Such factors as physiological functioning, diet, exercise, mental attitude, and environment, are considered when assessing health status. Patients are encouraged to become active agents in establishing and maintaining healthy balanced lifestyles. This proactive approach is a foundational cornerstone of naturopathic medicine.

\section{History}

The origin of naturopathic philosophy has been traced back to Hippocrates, who advanced the idea that by utilizing natural laws the human body could heal itself (Murray \& Pizzorno, 1991). The late 1960s and early 1970s brought disenchantment with many things, including conventional medicine. The failure of chronic health problems to respond adequately to the conventional approach shed light on the medical model's limitations. In the wake of this disillusionment, natural medicine gained renewed respect. By 1987 the government had recognized the Council on Naturopathic Medical Education as the official accrediting body for institutions of higher learning (Collinge, 1996).

\section{Naturopathy today}

With the advent of the 1990s came a directive from Congress instructing the government to create and support a new branch of the National Institute of Health: The Office of Alternative Medicine (Chowka, 1996). As a result of its newfound status, naturopathic medicine has begun to enjoy increased backing from government and industry in the form of funding for research and financial support for practice. For example, in 1994 Bastyr University received a government grant of $\$ 840,000$ to establish an alternative medicine research center for HIV/ AIDS (Bastyr University, 1998). The university also established and manages the nation's first publicly funded natural medicine clinic located in Kent, Washington (Bastyr University, 1998). A growing number of medical insurance companies now provide for the services of a naturopathic physician.

Eleven states currently enforce licensure standards (Alaska, Arizona, Connecticut, Hawaii, Maine, Montana, New Hampshire, Oregon, Utah, Vermont, and Washington) for naturopathic physicians. Although specific requirements differ across states, in general, to receive licensure prospective physicians must possess undergraduate degrees (typically pre-med) and doctoral degrees in naturopathic medicine from an accredited college or university, and pass a professional board exam (Murray \& Pizzorno, 1991).

\section{Naturopathy and Professional Counseling as Partners}

There are several areas in which naturopathy and counseling share common ground. Both disciplines recognize and appreciate the mind-body connection as well as the potential impact of spiritual, environmental, and social factors on health. Professional counseling and naturopathic medicine are developmental in nature, with a focus on prevention and personal responsibility for wellness. The hope of both the naturopath and counselor is to empower those who seek assistance through education and the recognition of individuals' uniqueness. Active involvement with regard to selection of treatment goals and therapeutic interventions is highly encouraged. Both disciplines embrace an optimistic stance, believing that people not only have the capability of overcoming present challenges but also have the potential to reach beyond their premorbid state of functioning to achieve a higher level of wellness (Gordon, 1990).

Given the shared philosophy between naturopathy and counseling, it would appear that collaboration between the fields has the potential to provide enhanced holistic care. An exploration of possible questions resulting from a collaborative effort should be conducted to ensure that the welfare of clients is given highest priority. What are the challenges posed by such a partnership in the areas of counselor practice, training, and ethics?

\section{Practice}

One primary factor for consideration in the area of practice is that of "counselor-as-person." Much like the lay public, counselors' degrees of openness to alternative care will be influenced by their personal experiences, experiences of friends and family, and their knowledge base regarding the subject. Counseling professionals understand that their personal knowledge, values, and opinions impact the counseling process and thus the client. Therefore, counselors are challenged to explore their own attitudes and beliefs about naturopathic care and to expand their knowledge base before endeavoring to assist clients.

Following efforts to educate themselves, counselors then are faced with the task of identifying those clients who may benefit from naturopathic care. Furnham and Smith (1988) noted in their comparative study of patients who 
either chose a conventional or a homeopathic physician that people who sought alternative treatment fell into a category that labeled them as "hard to treat" by the conventional medical community. When compared to patients who chose a general medical practitioner, these patients possessed more critical attitudes about the ability of conventional doctors to meet their needs. In addition, they were judged as having a greater degree of neurosis than the "average" patient as evidenced by higher scores on a measure of psychological disturbance.

As counselors, we can reframe this negative interpretation by viewing clients' qualities as strengths rather than limitations. We can choose to view those who seek alternative care as people who have a greater sensitivity towards their body, are confident that they can make a difference in improving their health, and have a greater desire for long-term health. In general, clients who value an egalitarian therapeutic relationship (Hewer, 1983), aspire towards a greater degree of participation in health care decisions and the wellness process, and are less likely to passively accede to the treatments prescribed by their health care provider.

Clients who are attracted to naturopathic care may find themselves confused by the diverse health care choices now available to them. Professional conversations in the mental health community include the various aspects of supporting clients who are attempting to select an approach from among an array of alternative treatment options. Our charge, as counselors, is to sort out our role when dealing with clients who display a combination of physical and emotional symptoms. We are likely to encounter depression in clients who have illnesses that are difficult to diagnose or treat, or for which treatment is either unpleasant or not available. For example, Albrecht and Wallace (1998) highlighted the potential challenges encountered by clients who suffered from chronic fatigue syndrome and the role of counselors in assisting such clients. Though we should not present ourselves as naturopathic specialists, we can serve as detective, supporter, and educator for such clients. Clients can be given basic information on how to select an alternative health care provider for complementary care, where to find materials that explain treatment options, and how to decipher the results of research studies.

Counselors can assist clients through skills training aimed at the development of effective problem-solving and decision-making ability, as well as the ability to advocate for themselves within the general medical community. While many clients have learned to take a passive role, counselors can encourage an assertive stance based on the conviction that clients can learn to become experts on their own bodies, personal needs, and preferences. In the actual selection of courses of treatment, clients, counselors, and naturopaths have the opportunity to work cooperatively. Such empowerment is likely to lead to a better fit between clients and the treatments of choice.

\section{Training}

Licensed professional counselors and counselors-intraining could benefit by continuing education that includes an overview of alternative or naturopathic medicine. Traditionally, counselor education programs have encouraged students to learn about the physiological aspects of mental disorders and the psychopharmacological interventions that support conventional medicine's view of these disorders. Students receive guidance with regard to which clients should be referred to physicians or psychiatrists, how to refer to the conventional medical community, and how to support clients who are actively engaged in some type of medical intervention. Little, if any, course work is offered that would assist counselors in considering alternative medical approaches.

Recognition of the need to expand training opportunities is an important first step in strengthening the ability of professional counselors to meet the needs of today's clientele. In their discussion of possible trends in counseling and their implications for counselor training, Eriksen et al. (1997) drew specific attention to "the medicine-psychology intersection" and included within this content area the topic of alternative medical approaches. If the counseling profession were to embrace such a proposal, what then would counselor educators need to impart to their students about natural approaches and who would provide training for the counselor educators? The answer to this latter question is likely to be found through interdisciplinary collaboration with the naturopathic medical community.

A mutual exchange between educators from both disciplines has the potential to illuminate a central body of knowledge, key concepts, pertinent issues, and best practices that are considered foundational to naturopathy. In preparing students to work with clients who prefer an alternative approach, counselor educators would have guidance in choosing legitimate and respected information sources to assist students in understanding the field of naturopathic medicine. Included among the tasks in educating counselors-in-training are: (a) increasing students' awareness, (b) imparting a basic understanding of the approach, (c) highlighting commonalities and differences between naturopathy and conventional medicine, (d) exploring the efficacy of various naturopathic medical treatment approaches, and (e) identifying trusted information sources. Students will also need tools to recognize legitimate naturopathic practitioners and have the ability to distinguish between clients who may or may not benefit from a naturopathic medical approach. 
For those clients who ultimately seek out the alternative health care services, counselors-in-training must know how to support them in their efforts to enhance wellness. In some respects, this may be challenging in that a naturopathic approach often brings relief through a more gradual healing and restoration process when compared to conventional medicine's interventions, which are aimed at timely suppression of symptoms. Clients new to the approach may be too hasty in concluding that the naturopathic intervention failed to bring about the desired end product and prematurely terminate treatment. Should clients be encouraged, then, to continue with their prescribed treatment regime? With this and other concerns, students must also be taught to review possible ethical considerations.

\section{Ethics}

A primary concern for the counseling profession is the alignment of ethical standards across disciplines. Interdisciplinary collaboration can occur only in the presence of agreement that protection of client rights is given priority above all else. In addition, appropriate boundaries between the professions need to be made definite. For example, just as counselors must refrain from reaching beyond the scope of their training and expertise with regard to medical issues, naturopaths must be sensitive to their own limitations in the area of mental health. Although they may have taken as many as seven courses in counseling and communication skills (Collinge, 1996), naturopaths should refer those clients whose mental health needs surpass the training they received in medical school. Ongoing conversation between the two professions has the potential to clarify similar issues and develop suitable parameters.

Another ethical challenge that may emerge in counseling is related to the problem-solving process. As with any presenting problem, it is the counselors' charge to assist clients in exploring an array of possible solutions. At this stage of the counseling process, the dilemma that could unfold for counselors is whether or not the clients' issues are connected to physical or mental health. The following questions remain unanswered in counseling practice: (a)
What responsibility, if any, do counselors have to interject naturopathic medical approaches among the viable courses of action being reviewed? (b) If clients are unfamiliar with the naturopathic approach, should counselors impart information and offer introductory educational materials? And finally, (c) should counselors who are unfamiliar with naturopathy, or uncomfortable with the approach altogether, refer clients to counselors who can help them? The answers to these questions can best be found through professional counseling's ongoing dialogue, study, and research, which can in turn inform an ethical "best practices" approach.

Unregulated nonprescription health care products can pose a practical and ethical challenge for counselors. As alternative care increases in popularity, so too will the numbers of clients that counselors serve who struggle with common problems such as insomnia, depression, and anxiety, and likewise are attracted to natural approaches to self-treatment. Tempted by the latest natural remedy reviewed in the popular media, clients may well consider experimenting with herbal remedies and food supplements. As counselors, supporting such actions seems ill advised given the average person's limited knowledge. However, the naturopathic physicians are experts who can thoroughly address issues such as the validity of various treatment approaches for specific conditions, and how to locate reliable sources for quality remedies and supplements. Clients who wish to pursue the use of these products should be referred to the professionals who have the specific expertise.

On the occasion when referral to naturopathic physicians would be appropriate, ethics would direct counselors to be certain that the doctors are properly educated and trained, and are considered a respected member of the professional community. Several reputable sources of information are available to assist counselors in making this determination. Contacting an organization charged with safeguarding the profession, such as the National Association of Naturopathic Physicians, is one means of ascertaining whether or not naturopaths are members in good standing. If in a state with licensure or practice laws, counselors also can contact the Department of Health's professional licensing division. 


\section{Summary}

With increasing frequency, clients are seeking natural solutions to health concerns. As naturopathic medicine's validity is established in the health care community, collaboration between counseling and naturopathic medicine seems worthy of exploration for all concerned. With client well-being taking center stage, it will be important for counselors to understand the "what, when, and how" of alternative medical treatment and referral decisions. Interdisciplinary dialogue, especially with naturopathy's educational community, has the potential to clarify and inform an ethical "best practices" approach to counselor training and service provision for those clients who would benefit from holistic approaches.

\section{References}

Albrecht, F., \& Wallace, M. (1998). Detecting chronic fatigue syndrome: The role of counselors.Journal of Counseling and Development, 76(2), 183-188.

American Association of Naturopathic Physicians. (2002). [Web site]. http:/ / www.naturopathic.org

Bar, B. (1998). The effect of holism on the health care system. Hospital Materiel Management Quarterly, 20(1), 70-82.

Bastyr University. (1998). [Web site]. http:/ / www.bastyr.edu.

Chowka, P. B. (1996). What is naturopathic medicine? [Web site]. http:/ / healer.infinite.org/Naturop...sician/ Tradition INaturopathy.html, 1-3.

Collinge, W. (1996). The American Holistic Health Association complete guide to alternative medicine. New York: Warner Books, Inc.

Collins, G. (Ed.). (1997). Alternative medicine, wellness, and healing: What's on the horizon? Christian Counseling Today, 5(3).

Delbanco, T. L. (1994). Commentary on "Placebo as a Treatment for Depression." Neuropsychopharmacology, 10(4), 279-280.

Eriksen, K., Artico, C., Schmitt, J., Quinn, M., Waters, S., \& Wilson, P. (1997, Fall). Trends incounseling. ACES Spectrum, 58(1), 7-8.
Farberman, R. K., \& Haber, S. (1998, May). Alternative medicine: Much promise, little data. APA Monitor, p. 11.

Flint, V. (1998). How to use alternative and complementary medicine. WebMD [On-line],Available: http: / / my.webmd.com/content/dmk/ dmk_article_58289

Furnham, A., \& Forey, J. (1994). The attitudes, behaviors and beliefs of patients of conventionalvs. complementary (alternative) medicine. Journal of Clinical Psychology, 50(3), 458-469.

Furnham, A., \& Smith, C. (1988). Choosing alternative medicine: A comparison of the beliefs of patients visiting a general practitioner and a homeopath. Social Science Medicine, 26(7), 685-689.

Gellert, G. (1994). Global explanations and the credibility problem of alternative medicine. The Journal of Mind-Body Health, 10(4), 60-67.

Gordon, J. S. (1990). Holistic medicine and mental health practice: Toward a new synthesis. American Journal of Orthopsychiatry, 60(3), 357-370.

Gruman, J. C. (1995). Should alternative medicine stay alternative? The Journal of Mind-Body Health, 11(4), 65-70.

Haber, S. (1998, May). When patients' needs go beyond traditional care. APA Monitor, p. 11.

Hemmings, A. (2000). Counseling in primary care: A review of the practice evidence. British Journal of Guidance \& Counseling, 28(2), 233253.

Hewer, W. (1983). The relationship between the alternative practitioner and his patient. Psychotherapy and Psychosomatics, 40, 172-180.

Johnson, T. B. (1997, December). [Review of the book Hypericum and depression]. The National Association of School Psychologists Communique, 26(4), 20-21.

Lyddon, W. J. (1987). Emerging views of health: A challenge to rationalist doctrines of medical thought. The Journal of Mind and Behavior, 8(3), 365-394.

Murray, M. T., \& Pizzorno, J. E. (1991). Encyclopedia of natural medicine. Rocklin, CA: Prima Publishing.

Papadopoulos, L., \& Bor, R. (1995). Counseling psychology in primary care: A review. Counseling Psychology Quarterly, 8(4), 291-303.

Wetzel, M. S., Eisenberg, D. M., \& Kaptchuk, T. J. (1998). Courses involving complementary and alternative medicine at U. S. Medical schools. Journal of the American Medical Association, 280(9), 784-787. 